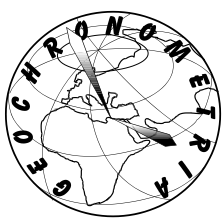

\title{
LONG-TERM SUMMER TEMPERATURE VARIATIONS IN THE PYRENEES FROM DETRENDED STABLE CARBON ISOTOPES
}

\author{
JAN ESPER ${ }^{1}$, OLIVER KONTER ${ }^{1}$, PAUL J. KRUSIC $^{2}$, MATTHIAS SAURER ${ }^{3}$, \\ STEFFEN HOLZKÄMPER ${ }^{2}$ and ULF BÜNTGEN ${ }^{4,5,6}$ \\ ${ }^{\text {I} D e p a r t m e n t ~ o f ~ G e o g r a p h y, ~ J o h a n n e s ~ G u t e n b e r g ~ U n i v e r s i t y, ~} 55099$ Mainz, Germany \\ ${ }^{2}$ Department of Physical Geography and Quaternary Geology, Stockholm University, 10691 Stockholm, Sweden \\ ${ }^{3}$ Paul Scherrer Institut, 5232 Villigen, Switzerland \\ ${ }^{4}$ Swiss Federal Research Institute WSL, 8903 Birmensdorf, Switzerland \\ ${ }^{5}$ Oeschger Centre for Climate Change Research, University of Bern, 3012 Bern, Switzerland \\ ${ }^{6}$ Global Change Research Centre AS CR, v.v.i., Bëlidla 986/4a, CZ-60300 Brno, Czech Republic
}

Received 28 July 2014

Accepted 6 February 2015

\begin{abstract}
Substantial effort has recently been put into the development of climate reconstructions from tree-ring stable carbon isotopes, though the interpretation of long-term trends retained in such timeseries remains challenging. Here we use detrended $\delta^{13} \mathrm{C}$ measurements in Pinus uncinata treerings, from the Spanish Pyrenees, to reconstruct decadal variations in summer temperature back to the $13^{\text {th }}$ century. The June-August temperature signal of this reconstruction is attributed using decadally as well as annually resolved, $20^{\text {th }}$ century $\delta^{13} \mathrm{C}$ data. Results indicate that late $20^{\text {th }}$ century warming has not been unique within the context of the past 750 years. Our reconstruction contains greater amplitude than previous reconstructions derived from traditional tree-ring density data, and describes particularly cool conditions during the late $19^{\text {th }}$ century. Some of these differences, including early warm periods in the $14^{\text {th }}$ and $17^{\text {th }}$ centuries, have been retained via $\delta^{13} \mathrm{C}$ timeseries detrending - a novel approach in tree-ring stable isotope chronology development. The overall reduced variance in earlier studies points to an underestimation of pre-instrumental summer temperature variability derived from traditional tree-ring parameters.
\end{abstract}

Keywords: Climate change, paleoclimatology, stable isotope geochemistry, tree-rings, Europe.

\section{INTRODUCTION}

Tree-ring $\delta^{13} \mathrm{C}$ records have been used to reconstruct various climate parameters including temperature (Treydte et al., 2009), precipitation (Bale et al., 2011), drought (Kress et al., 2010), relative humidity (Edwards et al., 2008), and cloud cover (Gagen et al., 2011). However, the assessment of potential low frequency trends in these climate parameters, using tree-ring stable isotope

Corresponding author: J. Esper

e-mail: esper@uni-mainz.de data, remains challenging as the isotope records are typically based on (i) few trees and (ii) pooled wood samples (mixed material from different trees prior to mass spectrometer measurement) (Borella et al., 1998). The pooling procedure limits the ability to analyze varying $\delta^{13} \mathrm{C}$ levels among individual trees as well as any potential underlying age-trends that might obscure long-term climate signals (Esper et al., 2010; Dorado Liñán et al., 2011; Hangartner et al., 2012). As a result, climate reconstructions derived from detrended tree-ring $\delta^{13} \mathrm{C}$ data, in which $\delta^{13} \mathrm{C}$ level differences and age-trends have been analyzed and, if detected, removed, are largely missing from the literature. 
The investigation of between-tree $\delta^{13} \mathrm{C}$ level differences and $\delta^{13} \mathrm{C}$ age-trends requires processing single trees individually throughout the time-demanding and expensive procedure of sample preparation and mass spectrometry measurement. This can realistically be achieved by reducing the temporal resolution of $\delta^{13} \mathrm{C}$ measurement from annual to decadal or even lower time steps (Edwards et al., 2008). Here we present the first such experiment, comprising 31 individual $\delta^{13} \mathrm{C}$ measurement series from living and dead Pinus uncinata trees, from a high elevation site in the Spanish Pyrenees. All trees were treated individually, at decadal resolution, to develop a dataset containing $1007 \delta^{13} \mathrm{C}$ measurements spanning the past millennium. The 31 decadally resolved $\delta^{13} \mathrm{C}$ timeseries (each representing a single tree) cannot be used to reconstruct annual extremes, but permit the analysis and treatment of $\delta^{13} \mathrm{C}$ level differences and age-trends to develop a detrended stable isotope chronology containing long-term climate variations back to the $13^{\text {th }}$ century.

Statistical calibration and verification of such a record, however, requires annually resolved $\delta^{13} \mathrm{C}$ measurements during the period of overlap with instrumental data. This objective is addressed by combining the decadally resolved $\delta^{13} \mathrm{C}$ data with 545 annually resolved $\delta^{13} \mathrm{C}$ measurements from a sub-sample of Pinus uncinata trees covering the $20^{\text {th }}$ century (Konter et al., 2014). The high frequency climate signals of $\delta^{13} \mathrm{C}$ (and $\delta^{18} \mathrm{O}$ from the same trees) have been explored in detail in Konter et al. (2014) including assessments of the effects of differing $\delta^{13} \mathrm{C}$ correction procedures, to account for the Suess effect (Suess, 1955), on the calibration schemes. We here build on these results and develop a millennial-scale reconstruction based on decadally resolved, detrended, $\delta^{13} \mathrm{C}$ measurements, with the climate signal attributed to the comparison of annually resolved $\delta^{13} \mathrm{C}$ measurements with instrumental data. The reconstruction is compared to extant long-term estimates of warm season temperature variability from the Spanish Pyrenees, based on maximum latewood density (MXD) data.

\section{2. $\delta^{13}$ C DATA, DETRENDING AND CALIBRATION METHODS}

Increment cores from living trees and dry-dead wood were collected (Fig. 1) to develop a continuous, millennium-length Pinus uncinata composite chronology for the Central Pyrenees (Büntgen et al., 2008). The sampling site is located near lake Gerber $\left(42^{\circ} 38^{\prime} \mathrm{N}, 1^{\circ} 06^{\prime} \mathrm{E}\right)$ at the upper treeline (2400 $\mathrm{m}$ a.s.1.), where traditional tree-ring width (TRW) and MXD data have been shown to contain a summer temperature signal (Büntgen et al., 2010). From a total of several hundred Pinus uncinata sampled during several field campaigns, 31 trees were used to develop a stable carbon isotope ratio chronology spanning the past $700+$ years with a fairly stable temporal distribution, ranging from 5 trees in 1300 C.E. to 13 in 2000 C.E. (bottom panel of Fig. 2).
Increment cores were sectioned into decadal blocks (1991-2000, 1981-1990, ...) using a scalpel and processed individually to quantify the ${ }^{13} \mathrm{C} /{ }^{12} \mathrm{C}$ ratios in the wood samples (Esper et al., 2010). From five of the 31 trees, this procedure was applied at annual resolution over the 1901-2009 period so that the resulting $\delta^{13} \mathrm{C}$ timeseries from this sub-sample is decadally resolved before 1901 and annually resolved thereafter (Konter et al., 2014). We extracted $\alpha$-cellulose from the wood samples, homogenized and freeze dried the cellulose, and measured the ${ }^{13} \mathrm{C} /{ }^{12} \mathrm{C}$ ratios using an isotope ratio mass spectrometer, interfaced elemental analyzer, following standard procedures (Boettger et al., 2007; Battipaglia et al., 2008).

The isotope ratios are expressed in the conventional $\delta$ notation in parts per thousand (\%o) relative to the Vienna Pee Dee Belemnite standard. The resulting $\delta^{13} \mathrm{C}$ timeseries were corrected to account for atmospheric changes in ${ }^{13} \mathrm{C} /{ }^{12} \mathrm{C}$ composition due to combustion of fossil fuels ( $\sim 1.8 \%$ from $1850-2009)$ and discrimination changes under elevated $\mathrm{CO}_{2}$ concentrations (0.0073\%o/ppmv $\mathrm{CO}_{2}$ ) (Kürschner, 1996). In addition to this "Kur" correction we also discuss results based on the ${ }^{13} \mathrm{C} /{ }^{12} \mathrm{C}$ atmospheric correction (Atm), as well as additional plant physiological responses at the leaf level $\left(0.02 \%\right.$ oppmv $\mathrm{CO}_{2}$; Fen) (Feng and Epstein, 1995; overview in Treydte et al., 2009). Detailed assessments of the differently corrected $\delta^{13} \mathrm{C}$ timeseries and calibration against instrumental climate data are reported in Konter et al. (2014).

The $\delta^{13} \mathrm{C}$ timeseries were detrended using dendrochronological techniques (Cook and Kairiukstis, 1990) to account for level differences among single trees and agetrends inherent to the timeseries (Esper et al., 2010). A detrended $\delta^{13} \mathrm{C}$ chronology was developed by (i) aligning the $\delta^{13} \mathrm{C}$ measurements prior to 1850 C.E. by biological age (to assess age-trend; Fig. 2a), (ii) removing $\delta^{13} \mathrm{C}$ agetrends over the first 200 years of the trees' lifespans by calculating residuals from fitted exponential functions (Fig. 2b), (iii) removing additional $\delta^{13} \mathrm{C}$ level differences of tree-rings older than 200 years by calculating residuals

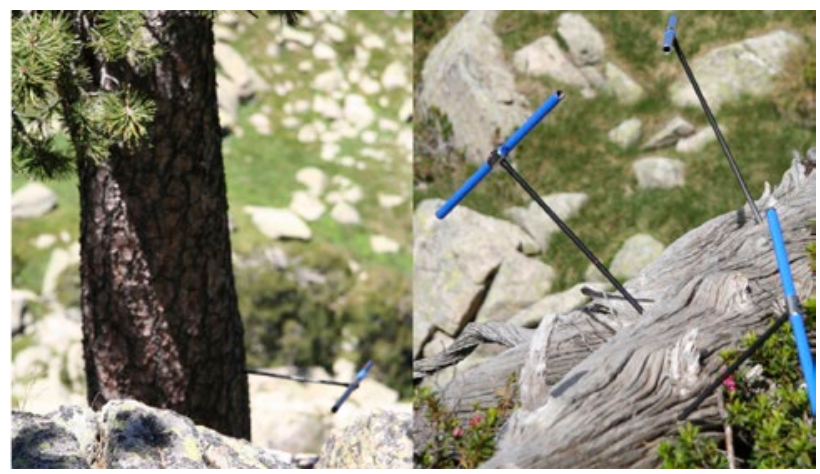

Fig. 1. Increment borers used to sample $5 \mathrm{~mm}$ diameter cores from living (left) and dead (right) Pinus uncinata near the timberline in the Spanish Pyrenees. 


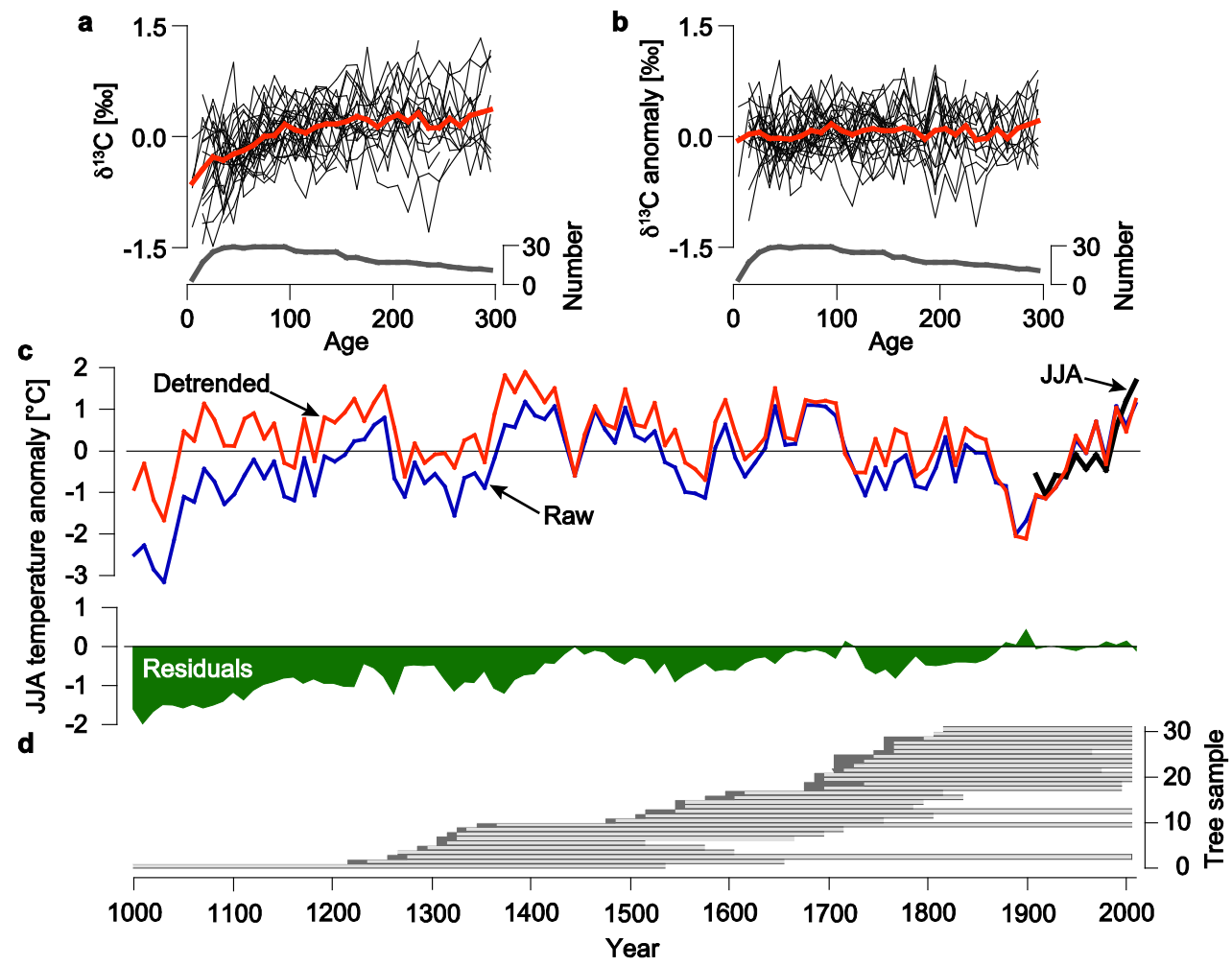

Fig. 2. $\delta^{13} \mathrm{C}$ age-trend detection, correction, and chronology characteristics. (a) The raw $\delta^{13} \mathrm{C}$ measurement series of 31 trees (black) and their mean (red) after alignment by cambial age. The data prior to $1850 \mathrm{C}$.E. are shown to avoid biases due to modern $\delta^{13} \mathrm{C}$ correction procedures. Measurement series are expressed as anomalies with respect to the mean values over the years 1-200. Bottom panel shows the replication of the agealigned data, including an initial increase up to cambial ages of $\sim 30$ years due to missing juvenile rings in core samples. (b) Same as in (a), but for the exponential and straight line detrended data. (c) Raw and detrended arithmetic mean chronologies after regression against regional JJA temperatures. Post-1850 data were Kur corrected, and chronology variance changes stabilized to remove effects due to replication changes (see Methods). Bottom panel shows the residual timeseries between the raw and detrended chronologies. (d) Temporal coverage of individual trees throughout the past millennium. Dark grey indicates the number of missing innermost rings on core samples.

from the mean $\delta^{13} \mathrm{C}$ values of these mature rings, and (iv) calculating arithmetic means of the detrended $\delta^{13} \mathrm{C}$ timeseries. Temporal variance changes in the resulting chronology, due to replication changes from $n=13$ trees in the $20^{\text {th }}$ century to $\mathrm{n}<5$ trees in the $13^{\text {th }}$ century, were removed by calculating ratios from running, 110-year (11 decadal values) standard deviations, derived from the first-differenced $\delta^{13} \mathrm{C}$ chronology (details in Frank et al., 2007).

The final, detrended and variance stabilized, $\delta^{13} \mathrm{C}$ chronology was calibrated over the 1901-2009 period against gridded (CRU3.1) June-August (JJA) temperature data averaged over $0-3^{\circ} \mathrm{E} / 38-43^{\circ} \mathrm{N}$ (Mitchell and Jones, 2005; Konter et al., 2014). Calibration was performed using both the annually resolved proxy and instrumental data, as well as the decadally resolved data - with the JJA temperatures averaged to meet the decadal resolution of the $\delta^{13} \mathrm{C}$ timeseries. Split calibration/verification trials were performed over the 1951-2009 and 1901-1950 intervals, and the reduction of error (RE) and coefficient of efficiency (CE) calculated to estimate statistical skill of the proxy/climate association (Cook et al., 1994). For temperature reconstruction, the $\delta^{13} \mathrm{C}$ chronology was regressed against the decadally resolved JJA temperature data (Esper et al., 2005). Reconstruction uncertainties were estimated by calculating the standard error (SE) from repeated ( $>100$ times) calibration trials using differently replicated $(\mathrm{n}=13, \mathrm{n}=12, \ldots, \mathrm{n}=3) \delta^{13} \mathrm{C}$ chronologies over the $20^{\text {th }}$ century to account for the replication decline back in time. Finally, the $\delta^{13} \mathrm{C}$ based JJA temperature reconstruction is compared to a MXD based reconstruction that was originally calibrated against JJA maximum temperatures (Büntgen et al., 2008) and a multi-site MXD based reconstruction calibrated against May-September mean temperatures (Dorado Liñán et al., 2012). In this comparison, the temporal resolution of the MXD timeseries was reduced to match the decadally resolved $\delta^{13} \mathrm{C}$ record presented here.

\section{RESULTS AND DISCUSSION}

The removal of $\delta^{13} \mathrm{C}$ level differences and age-trends resulted in a millennium-long record indicating higher chronology levels back in time, compared to its non- 
detrended "raw" counterpart (Fig. 2). The detrending procedure corrected the systematically lower $\delta^{13} \mathrm{C}$ values of biologically younger rings likely triggered by the (i) uptake of $\mathrm{CO}_{2}$ enriched ambient air from soil respiration (Francey and Farquhar, 1982), and (ii) decreased hydraulic resistances and higher stomatal conductance of smaller trees (McDowell et al., 2002). As a consequence, the residual timeseries, between the raw and detrended chronologies, increases from $-0.26^{\circ} \mathrm{C}$ in the $17^{\text {th }}$ century to $-0.74^{\circ} \mathrm{C}$ in the $13^{\text {th }}$ century. However, it is important to note, the early periods of the chronology are represented by fewer trees (one before 1230 C.E.). The detrended $\delta^{13} \mathrm{C}$ chronology produces higher values during late $15^{\text {th }}$, late $14^{\text {th }}$ and early $13^{\text {th }}$ centuries, compared to the late $20^{\text {th }}$ century.

Calibration of the annually resolved $20^{\text {th }}$ century $\delta^{13} \mathrm{C}$ data against instrumental temperatures revealed a clear seasonal pattern including highest correlations with June, July, and August temperatures (Fig. 3a). The correlation against mean JJA temperatures is $r=0.56$, though splitperiod calibration/verification trials indicate a weakening of this association back over the $20^{\text {th }}$ century (Fig. $\mathbf{3 b}$; $r_{1951-2009}=0.47$ to $r_{1901-1950}=0.28$ ), a finding that is likely related to a loss of skill in the meteorological network during the first half of the $20^{\text {th }}$ century (see Konter et al., 2014 for more detail on climate responses and effects of $\delta^{13} \mathrm{C}$ correction procedures).

The JJA temperature signal is stronger at the decadal scale $\left(R^{2}=0.70 ; \mathrm{p}<0.05\right)$, compared to the annual data $\left(R^{2}=0.32 ; \mathrm{p}<0.001\right)$ (Fig. 4). However, the lowresolution calibration is based on much fewer degrees of freedom $(\sim 4)$ compared to the high-resolution approach ( $\sim 64)$, owing to the reduced number of correlation pairs (11 decades compared to 109 annual values over 1901-
2009) and an increased lag-1 autocorrelation (0.56 compared to 0.46$)$. The RE ( 0.66 for decadal and 0.62 for annual) and $\mathrm{CE}$ results $(0.64$ and 0.28$)$ indicate the $\delta^{13} \mathrm{C}$ timeseries match the JJA target data reasonably well, so

a
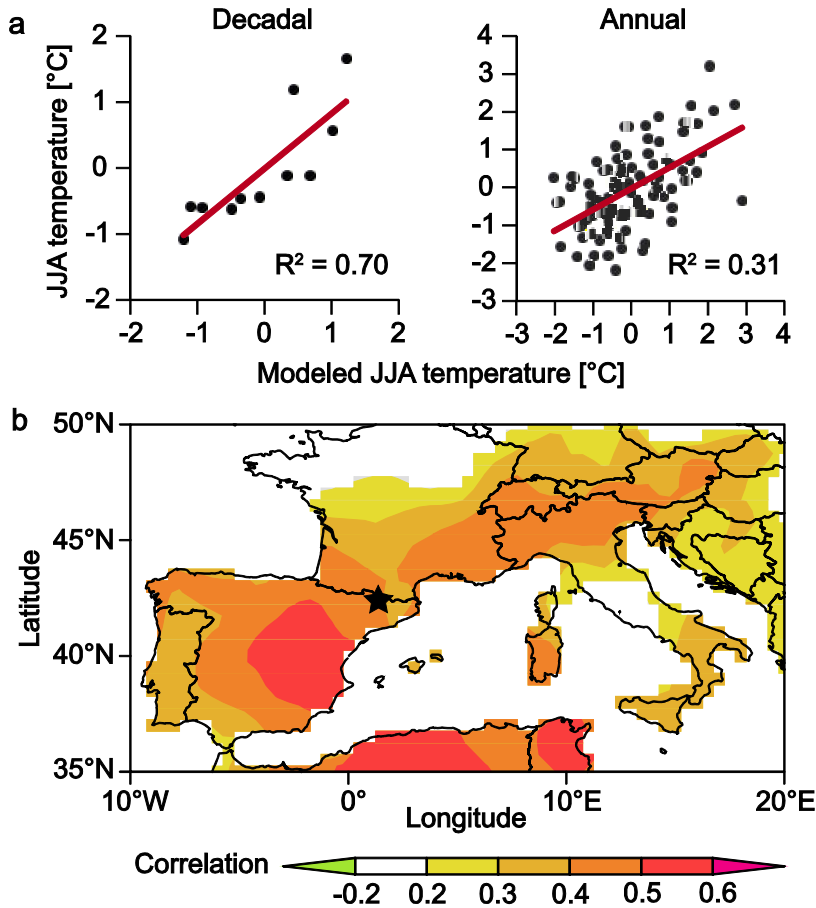

Fig. 4. ${ }^{13} \mathrm{C}$ calibration against regional JJA temperatures. (a) Distribution and linear trends of the decadally (11 values) and annually resolved (109 values) $\delta^{13} \mathrm{C}$ and JJA temperature data over the 19012009 period. (b) JJA temperature correlation field of the annually resolved $\delta^{13} \mathrm{C}$ data. Star indicates the location of the sampling site.

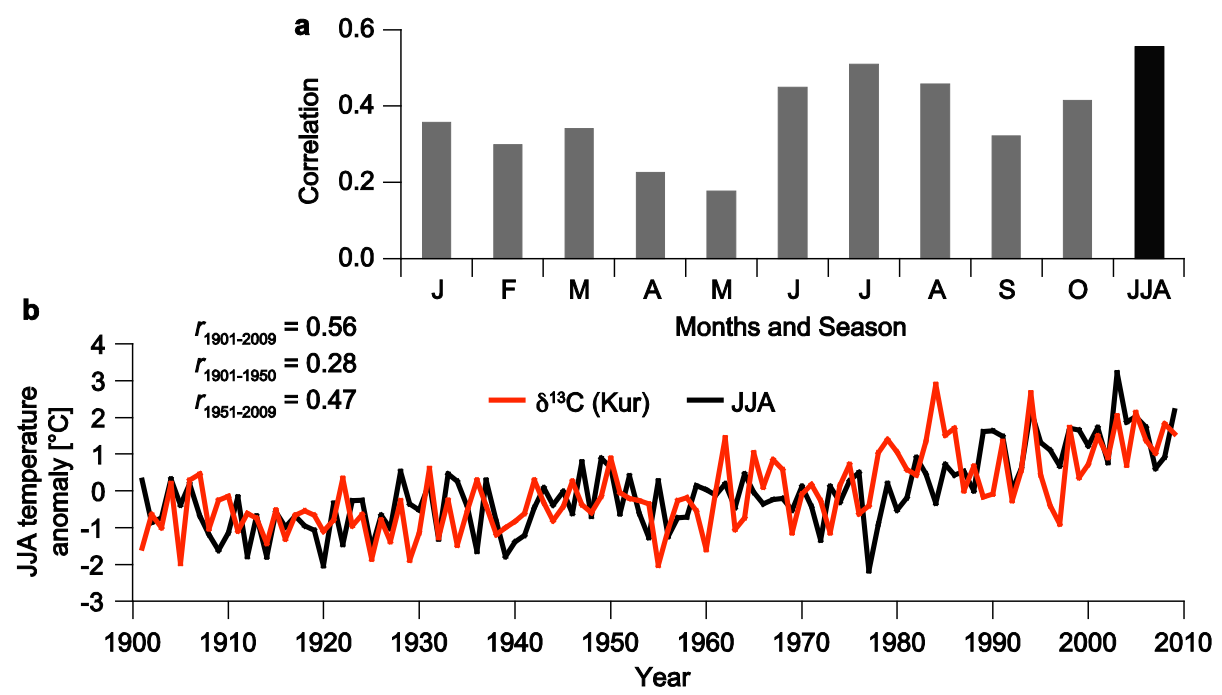

Fig. 3. Calibration of the annually resolved $\delta^{13} \mathrm{C}$ data. (a) Correlation results between the monthly (January to October) and seasonal (JJA) temperature (CRU3.1) and the Kur corrected $\delta^{13} \mathrm{C}$ data over the 1901-2009 period. (b) The annually resolved $\delta^{13} \mathrm{C}$ timeseries (red) scaled to match the mean and variance of the JJA temperature timeseries (black). 
that a reconstruction based on this proxy would have statistical skill. The spatial pattern of the signal $(r>0.4)$ indicates a predominating influence of Mediterranean synoptic systems on the pine isotopic composition, extending from Northern Africa into the Iberian Peninsula and eastwards over the European Alps (Fig. 4b).

The detrended $\delta^{13} \mathrm{C}$ reconstruction exhibits decadal scale summer temperature variations ranging from $+1.57^{\circ} \mathrm{C}$ in the 1390 s C.E. to $-1.83^{\circ} \mathrm{C}$ in the 1890 s C.E. (Fig. 5a). The uncertainty band accompanying this reconstruction back to $\sim 1260$ C.E., the first decade represented by three trees, shows most of the temperature variations over the past 750 years did not deviate significantly from the 1961-1990 mean, however. The uncertainty band is increasing back in time as a function of the reduced replication of earlier chronology periods. Whereas more recently reconstructed temperatures $\left(+1.01{ }^{\circ} \mathrm{C}\right.$ from $2001-$ 2009) have been cooler than the late $14^{\text {th }}$ and $15^{\text {th }}$ centuries, the difference between these periods is insignificant.

The new $\delta^{13} \mathrm{C}$ based reconstruction shares some characteristics of existing reconstructions derived from MXD data, including a long-term cooling trend from the late $14^{\text {th }}$ to the mid $19^{\text {th }}$ centuries (Fig. $5 \mathrm{~b}$ ). However, the high decadal scale summer temperature variance recorded in our $\delta^{13} \mathrm{C}$ based record exceeds the variance retained in the
MXD reconstructions that were originally calibrated against maximum temperatures (Büntgen et al., 2008) and extended growing season temperatures (Dorado Liñán et al., 2012). The reduced variability of the existing records likely arises from the application of detrending procedures to MXD datasets obtained from predominately living trees (Esper et al., 2003). Consequently, the MXD based reconstructions do not pick up the cool late $19^{\text {th }} /$ early $20^{\text {th }}$ century conditions reflected in the early instrumental record (see black curves in Fig. 5b).

Our new $\delta^{13} \mathrm{C}$ based reconstruction seems to capture $20^{\text {th }}$ century temperature trends better than the existing MXD records. The performance improvement is largely determined by the applied atmospheric $\mathrm{CO}_{2}$ correction. We considered the Kur, Fen, and Atm corrections in our reconstruction attempts, choosing the annually resolved reconstruction containing the least trend in residuals after calibration against instrumental summer temperatures $\left(-0.01^{\circ} \mathrm{C} /\right.$ decade for Kur, $+0.06^{\circ} \mathrm{C} /$ decade for Fen, and $-0.10^{\circ} /$ decade for Atm; Fig. 6). However, the decision to favor one $\delta^{13} \mathrm{C}$ correction scheme over another is generally not well justified (Treydte et al., 2009), and perhaps represents the most significant constraint of the new summer temperature reconstruction presented here.

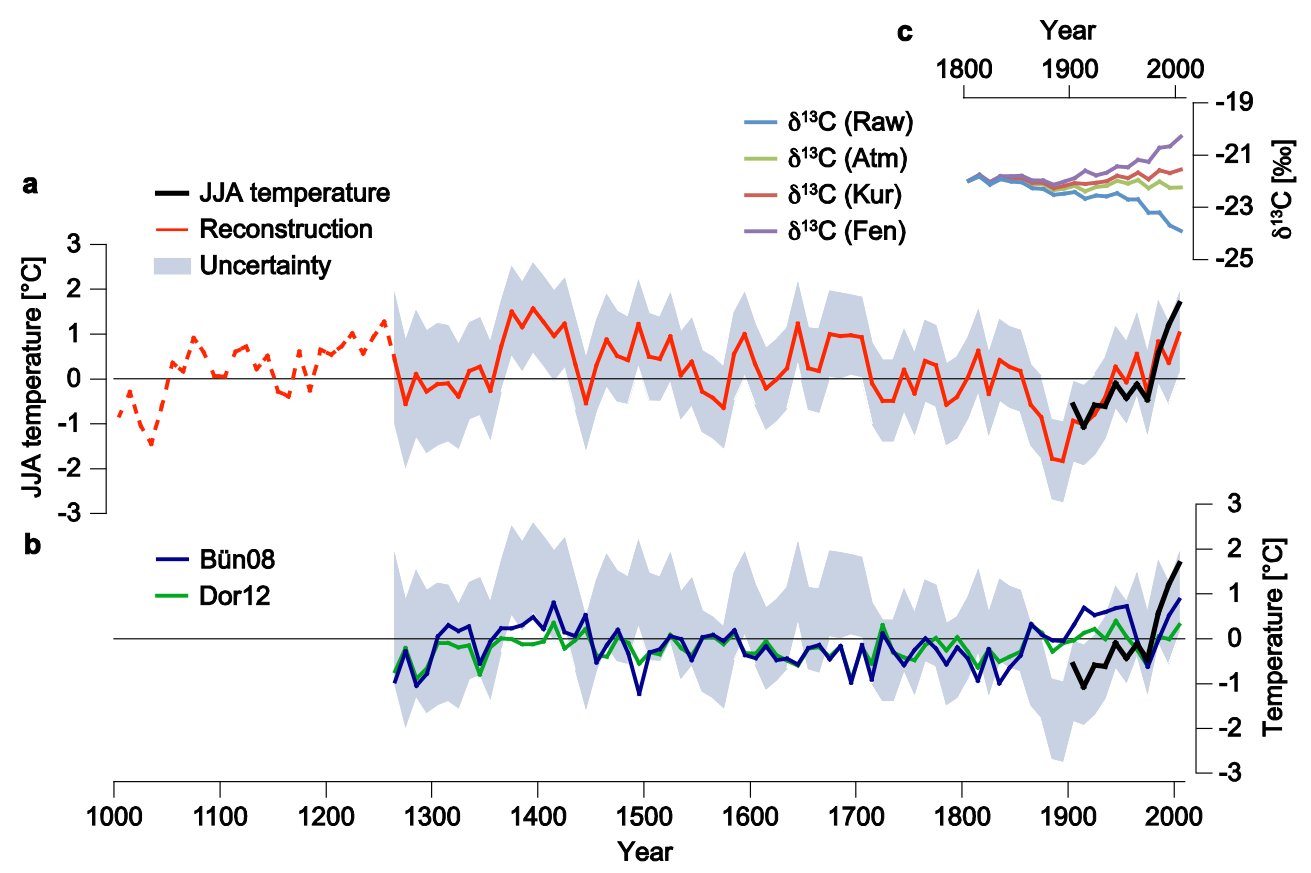

Fig. 5. $\delta^{13} \mathrm{C}$ based JJA temperature reconstruction and comparison with existing estimates. (a) Decadally resolved temperature reconstruction back to the $13^{\text {th }}$ century derived from regression against JJA temperatures. Dashed curve indicates the period prior to 1260 C.E. when sample replication falls below three trees. The SE uncertainty band is derived from calibration trials against JJA temperatures using less-replicated chronologies to assess climate signal strengths during earlier chronology periods (see Methods). (b) MXD based JJA maximum (Büntgen et al., 2008) and MaySeptember mean temperature (Dorado Liñán et al., 2012) reconstructions, plotted together with the regional JJA temperatures and uncertainty band from (a). All timeseries expressed as anomalies with respect to $1961-90$. (c) Recent $\delta^{13} \mathrm{C}$ chronology tails for the raw data and data after application of the Atm, Kur, and Fen corrections to account for atmospheric ${ }^{13} \mathrm{C} /{ }^{12} \mathrm{C}$ ratio and tree physiological effects. 


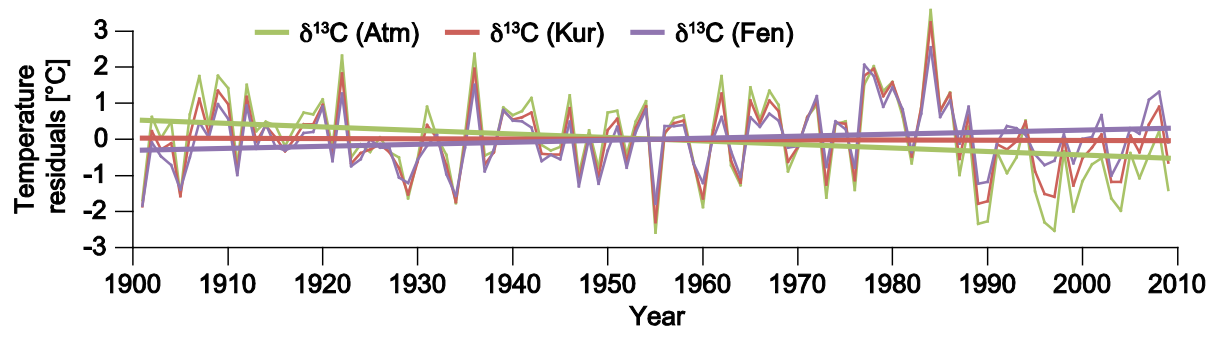

Fig. 6. Proxy/climate residuals. Annual residuals between the scaled Atm, Kur, and Fen corrected $\delta^{13} \mathrm{C}$ timeseries and the target JJA temperature timeseries (thin curves) shown together with the linear regression lines (bold curves) over the 1901-2009 period. Linear trends range from $0.10 \%$ decade for the Atm, $+0.06^{\circ} \mathrm{C} /$ decade for the Fen, to $-0.01^{\circ} \mathrm{C} /$ decade for the Kur corrected data.

\section{CONCLUSIONS}

The Spanish Pyrenees $\delta^{13} \mathrm{C}$ based reconstruction presented here shows warmer and more variable growing season temperatures during the Little Ice Age than previously described (Büntgen et al., 2008; Dorado Liñán et al., 2012). Developing this reconstruction required systematically removing lower $\delta^{13} \mathrm{C}$ values inherent to treerings younger than 200 years, that would otherwise lower the mean chronology levels during earlier periods of the past millennium, where these younger rings dominate the reconstruction. As a consequence, earlier warm periods during the late $14^{\text {th }}$ and $15^{\text {th }}$ centuries appear warmer, though not statistically significant, compared to the late $20^{\text {th }}$ century.

A major constraint of the new reconstruction is the substantial difference in recent temperature trends caused by post- $1850 \delta^{13} \mathrm{C}$ correction procedures. The correction applied here, accounting for atmospheric ${ }^{13} \mathrm{C} /{ }^{12} \mathrm{C}$ ratio and plant physiological effects, appeared most suitable as it produced a timeseries without any trend in residuals after regressing against instrumental temperatures. However, developing objective criteria for post-1850 correction, independent of the goodness of fit with instrumental target data, are needed to establish $\delta^{13} \mathrm{C}$ based reconstructions as an additional proxy for studying climate variations over past millennia.

\section{ACKNOWLEDGEMENTS}

Supported by the Mainz Geocycles Research Center. The $\delta^{13} \mathrm{C}$-based temperature reconstruction is available at: https://www.blogs.unimainz.de/fb09climatology/publications-jan-esper/

\section{REFERENCES}

Bale RJ, Robertson I, Salzer MW, Loader NJ, Leavitt SW, Gagen M, Harlan TP and McCarroll D, 2011. An annually resolved bristlecone pine carbon isotope chronology for the last millennium. Quaternary Research 76: 22-29, DOI 10.1016/j.yqres.2011.05.004.

Battipaglia G, Jäggi M, Saurer M, Siegwolf RTW and Cotrufo MF, 2008. Climatic sensitivity of $\delta^{18} \mathrm{O}$ in the wood and cellulose of tree rings: Results from a mixed stand of Acer pseudoplatanus $L$. and
Fagus sylvatica. Palaeogeogaphy, Palaeoclimatology, Palaeoecology 261: 193-202, DOI 10.1016/j.yqres.2011.05.004.

Boettger T, Haupt M, Knöller K, Weise SM, Waterhouse JS, Rinne KT, Loader NJ, Sonninen E, Jungner H, Masson-Delmotte V, Stievenard M, Guillemin M-T, Pierre M, Pazdur A, Leuenberger M, Filot M, Saurer M, Reynolds CE, Helle G and Schleser GH, 2007. Wood cellulose preparation methods and mass spectrometric analyses of $\delta^{13} \mathrm{C}, \delta^{18} \mathrm{O}$ and non-exchangeable $\delta^{2} \mathrm{H}$ values in cellulose, sugar and starch: an inter-laboratory comparison. Analytical Chemistry 79: 4603-4612, DOI 10.1021/ac0700023.

Borella S, Leuenberger M, Saurer M and Siegwolf R, 1998. Reducing uncertainties in $\delta^{13} \mathrm{C}$ analysis of tree rings: Pooling, milling, and cellulose extraction. Journal of Geophysical Research 103: 19519-19526, DOI . 10.1029/98JD01169

Büntgen U, Frank DC, Grudd H and Esper J, 2008. Long-term summer temperature variations in the Pyrenees. Climate Dynamics 31: 615-631, DOI 10.1007/s00382-008-0390-x.

Büntgen U, Frank DC, Trouet V and Esper J, 2010. Diverse climate sensitivity of Mediterranean tree-ring width and density. Trees 24: 261-273, DOI 10.1007/s00468-009-0396-y.

Cook ER and Kairiukstis LA, 1990. Methods of dendrochronology: applications in environmental science. Dordrecht, Kluwer: $394 \mathrm{pp}$.

Cook ER, Briffa KR and Jones PD, 1994. Spatial regression methods in dendroclimatology: A review and comparison of two techniques. International Journal of Climatology 14: 379-402, DOI . 10.1002/joc.3370140404

Dorado Liñán I, Gutiérrez E, Helle G, Heinrich I, Andreu-Hayles L, Planells O, Leuenberger M, Bürger C and Schleser G, 2011. Pooled versus separate measurements of tree-ring stable isotopes. Science of the Total Environment 409: 2244-2251, DOI 10.1016/j.scitotenv.2011.02.010.

Dorado Liñán I, Büntgen U, González-Rouco F, Zorita E, Montávez JP, Gómez-Navarro JJ, Brunet M, Heinrich I, Helle G and Gutiérrez E, 2012. Estimating 750 years of temperature variations and uncertainties in the Pyrenees by tree-ring reconstructions and climate simulations. Climate of the Past 8: 919-933, DOI 10.5194/cp-8919-2012.

Edwards TWD, Birks SJ, Luckman BH and MacDonald GM, 2008. Climatic and hydrologic variability during the past millennium in the eastern Rocky Mountains and northern Great Plains of western Canada. Quaternary Research 70: 188-197, DOI 10.1016/j.yqres.2008.04.013.

Esper J, Cook ER, Krusic PJ, Peters K and Schweingruber FH, 2003. Tests of the RCS method for preserving low-frequency variability in long tree-ring chronologies. Tree-Ring Research 59: 81-98.

Esper J, Frank DC, Wilson RJS and Briffa KR, 2005. Effect of scaling and regression on reconstructed temperature amplitude for the past millennium. Geophysical Research Letters 32: L07711, DOI 10.1029/2004GL021236.

Esper J, Frank DC, Battipaglia G, Büntgen U, Holert C, Treydte K, Siegwolf R and Saurer M, 2010. Low-frequency noise in $\delta^{13} \mathrm{C}$ and $\delta^{18} \mathrm{O}$ tree ring data: A case study of Pinus uncinata in the Spanish Pyrenees. Global Biogeochemical Cycles 24: GB4018, DOI 10.1029/2010GB003772. 
Feng $\mathrm{X}$ and Epstein S, 1995. Carbon isotopes of trees from arid environments and implications for reconstructing atmospheric $\mathrm{CO}_{2}$ concentration. Geochimica et Cosmochimica Acta 59: 2599-2608, DOI 10.1029/2010GB003772.

Francey RJ and Farquhar GD, 1982. An explanation of ${ }^{13} \mathrm{C} /{ }^{12} \mathrm{C}$ variations in tree rings. Nature 297: 28-31, DOI 10.1038/297028a0.

Frank D, Esper J and Cook ER, 2007. Adjustment for proxy number and coherence in a large-scale temperature reconstruction. Geophysical Research Letters 34: L16709, DOI 10.1029/2007GL030571.

Gagen M, Zorita E, McCarroll D, Young GHF, Grudd H, Jalkanen R, Loader NJ, Robertson I and Kirchhefer A, 2011. Cloud response to summer temperatures in Fennoscandia over the last thousand years. Geophysical Research Letters 38: L05701, DOI 10.1029/2010GL046216.

Hangartner S, Kress A, Saurer M, Frank DC and Leuenberger M, 2012. Methods to merge overlapping tree-ring isotope series to generate multi-centennial chronologies. Chemical Geology 294-295: 127134, DOI 10.1016/j.chemgeo.2011.11.032.

Konter O, Holzkämper S, Helle G, Büntgen U and Esper J, 2014. Climate sensitivity and parameter coherency in annually resolved $\delta^{13} \mathrm{C}$ and $\delta^{18} \mathrm{O}$ from Pinus uncinata tree-ring data in the Spanish
Pyrenees. Chemical Geology 377: 12-19, DOI 10.1016/j.chemgeo.2014.03.021.

Kürschner K, 1996. Leaf stomata as biosensors of paleoatmospheric $\mathrm{CO}_{2}$ levels. LPP Contributions Series 5: 1-153.

Kress A, Saurer M, Siegwolf RTW, Frank DC, Esper J and Bugmann H, 2010. A 350 year drought reconstruction from Alpine tree ring stable isotopes. Global Biochemical Cycles 24: GB2011, DOI 10.1029/2009GB003613.

McDowell NG, Phillips N, Lunch C, Bond BJ and Ryan MG, 2002. An investigation of hydraulic limitation and compensation in large, old Douglas-fir trees. Tree Physiology 22: 763-774, DOI 10.1093/treephys/22.11.763

Mitchell TM and Jones PD, 2005. An improved method of constructing a database of monthly climate observations and associated highresolution grids. Internatinal Journal of Climatology 25: 693-712, DOI 10.1002/joc.1181.

Suess HE, 1955. Radiocarbon concentration in modern wood. Science 122: 415-417, DOI 10.1126/science.122.3166.415-a.

Treydte K, Frank DC, Saurer M, Helle G, Schleser G and Esper J, 2009. Impact of climate and $\mathrm{CO}_{2}$ on a millennium-long tree-ring carbon isotope record Geochimica et Cosmochimica Acta 73: 4635-4647, DOI 10.1016/j.gca.2009.05.057. 